\title{
DESIGNING TEACHERS' TRAINING ON ADOPTING OERS IN THEIR TEACHING
}

\author{
Maria Perifanou, \& Anastasios A. Economides \\ SMILE lab, University of Macedonia (Greece)
}

\begin{abstract}
During the covid-19, it became apparent the imperative need for openly available digital educational resources to be used in education which has been shifted to Online Remote Teaching and Learning. It is important for teachers to be able to utilize Open Educational Resources (OERs) in education. This paper develops a framework for designing Teachers' Training programmes on how to integrate OERs in the teaching practice. The framework consists from six modules: 1) Introduction to OERs, 2) Exploring \& Evaluating existing OERs, 3) Using OERs, 4) Communicating \& Sharing OERs, 5) developing OERs, and 6) Open Educational Practices (OEPs). The paper also defines OERs \& OEPs competence. Finally, educational policy authorities may use this framework to design training programmes for teachers on how to integrate OERs in their teaching.
\end{abstract}

Keywords: Digital skills, inclusive education, lifelong learning, OERs skills, teachers professional development.

\section{Introduction}

During March and April 2020, more than 1.5 billion learners in most countries of the world were forced to attend online instead of face-to-face classes due to the COVID-19 social isolation restrictions (UNESCO, 2020). Almost all teachers and students participated in the online classes from home. However, it became clear that another form of discrimination is appearing. Not all teachers and students have the required digital infrastructure and digital skills to participate in such an Online Remote Teaching and Learning (ORTL). Furthermore, classes, teaching methods, and educational material (e.g. textbooks, case studies, assignments, projects, bibliographies) were not tailored to ORTL. Most educational material were in printed copyrighted form. Thus, it became apparent the imperative need for openly available digital educational resources to be used in ORTL. The adoption of Open Educational Resources (OERs) would be a solution.

OERs are digital educational material (e.g., full courses, educational modules, recorded lectures, assessments, case studies, textbooks, bibliographies, videos, photos, audio, multimedia, software, apps, tools, websites, learning management systems- LMS, social media) that are free (or with light copyright restrictions) to everyone to (http://www.opencontent.org/definition/):

- Retain - keep on a copy of the resource;

- Revise - adapt and modify (e.g., translate into another language) the resource;

- Remix - combine a copy of the resource with other material to produce something new;

- Reuse - use a copy of the resource;

- Redistribute - share a copy of the resource.

However, teachers usually do not have the knowledge and skills to use OERs or even know all about OERs. Also, many teachers would like to adapt the educational resources to their students' experiences, knowledge as well the local and current environment and context (e.g., Blomgren, 2018; Kimmons, 2015). Educators need new skills and knowledge to make the most of OERs and ORTL (OECD, 2020). According to TALIS (2018) survey, only 34\% of teachers in the European Union have participated in any online training in the past year. Thus, teachers (pre-service and in-service) need to be trained on utilizing OERs into their teaching practice. In fact, UNESCO (2019) stresses the need to train in-service and pre-service teachers on accessing, using, adapting, creating, and sharing OERs. 
There is an urgent need to design teachers' training programs and curricula to develop teachers' knowledge and skills on all phases of utilizing OERs into their teaching. Initially, it is important that teachers are able to find and use OERs. However, it is not easy to find OERs. They are scattered all over the places. Although there are serious efforts to gather and categorize them (e.g., Merlot, 2020; OER Commons, 2020), it is not an easy task. Therefore, a training program should give teachers the necessary knowledge and skills to find and evaluate appropriate OERs for their specific language, discipline, subject, educational level, student's age etc. (e.g., OPENLang Network Platform, 2020; OPENLang Network Project, 2020). Similarly, the training program should equip teachers with knowledge and skills to use and manage existing OERs as well to develop new ones. Furthermore, the teachers should be able to perform all educational activities using Open digital technologies. For example, the teachers should be able to communicate and teach students using open-source videoconferencing platforms (e.g., BigBlueButton) and open-source learning management systems (e.g. Moodle).

Next, this paper proposes a syllabus for Teachers' Training programmes on how to exploit Open Educational Resources (OERs) in the teaching practice.

\section{Methodology}

Inspired by the Open FASUCICESA - CPF Framework for MOOCs \& OERs (Economides \& Perifanou, 2018), this paper proposes a framework for a teachers' training syllabus. Among other issues, the Open FASUCICESA - CPF Framework describes the actions that a user can openly do on a MOOC and/or an OER without cost, anywhere, and anytime. These actions are the following:

- $\quad$ Openly Find (Seek, Locate, Discover);

- $\quad$ Openly Access (View, Watch, Read, Listen, Hear);

- Openly Store (Save, Retain, Download, Copy, Duplicate, Print);

- Openly Use (Control, Manage, Select);

- Openly Create (Design, Develop, Produce, Construct, Build, Calculate, Solve, Modify, Alter, Change, Adapt, Revise, Translate, Mix, Integrate, Combine);

- $\quad$ Openly Interact (Communicate);

- Openly Collaborate (Cooperate, Co-Create);

- $\quad$ Openly Evaluate (Assess, Review, Critique, Rank);

- Openly Share (Distribute, Teach, Publish, Display, Present, Present, Display, Show);

- Openly Abandon (Quit, Drop Out, Leave, Depart) without any penalties, charges, fines, obligations, punishments etc.;

under the following three dimensions of openness:

- Open Cost (allow anyone to participate at no cost);

- Open Place (allow anyone to participate from anywhere).

- Open Time (allow anyone to participate anytime);

Grouping together related actions, this paper proposes the following taxonomy of OERs skills: i) Exploring \& Evaluating existing OERs, ii) Using OERs, iii) Communicating \& Sharing OERs, and iv) Developing OERs using Open digital technologies (e.g., open data, open software, open hardware, and open networks). Of course, a training program on OERs skills should also include introductory issues about OERs as well as sections on Open Educational Practices (OEPs). So, we propose the following syllabus:

\section{Introduction to OERs}

- Open Education;

- OERs Definitions;

- OERs Types;

- Open Licenses, Intellectual Property Rights and Copyrights;

- OERs' Benefits \& Advantages;

- OERs' Weaknesses \& Challenges;

- $\quad$ OERs Costs (Production, Curation, Updating, Delivering etc.);

\section{Exploring \& Evaluating existing OERs}

- Search for OERs;

- $\quad$ Find (or locate, discover) OERs, and identify their Intellectual Property Rights; 
- Access (or view, watch, read, listen) OERs;

- Browse and navigate OERs;

- Evaluate (or assess, measure, compare, rank) OERs, and select (choose) the most appropriate ones;

\section{Using OERs}

- Store (or save, curate, archive) OERs on smart devices, LMSs, and Open Repositories;

- Download and install OERs (e.g., apps) on smart devices, LMSs, and Open Repositories;

- Copy (or duplicate, backup, curate) OERs on smart devices, LMSs, and Open Repositories;

- Analyse (or examine, investigate) OERs;

- Use (or operate) OERs in teaching and learning;

- Manage (or organize, plan, schedule) OERs;

- Terminate (or quit, withdraw, drop out, leave, depart, abandon, delete, dispose) OERs;

\section{Communicating \& Sharing OERs}

- Interact \& communicate (synchronously and asynchronously) with students and peers (or discuss, question-answer, argue, debate, negotiate) about OERs;

- Participate in Open Communities of peers about OERs;

- Collaborate \& cooperate with students and peers about OERs;

- Share (or disseminate, distribute, teach, publish, upload) OERs with students and peers in Open Communities and Repositories;

- Teach (or present, demonstrate, show, describe, explain) OERs to students and peers;

- Support (or guide, feedback, advise) students and peers with OERs;

- Evaluate (or assess, test) students using OERs;

\section{Developing OERs}

- Design OERs;

- Develop (or create, produce, write, edit, construct, build, generate) OERs;

- Code (or program) OERs;

- Execute OERs (e.g., run and parameterize software);

- Modify (or transform, convert, alter, change, adjust, adapt, revise, translate) OERs;

- Combine (or mix, synthesize, integrate, assemble) OERs;

- Correct (or repair, fix/solve problems in) OERs;

- Apply open licenses and copyrights to OERs;

- Protect students and peers using OERs and from inappropriate OERs.

\section{Open Educational Practices (OEPs)}

- Open Pedagogies;

- Open Teaching Methods \& Practices (e.g., Autonomous \& Self-Regulated Learning, Collaborative \& Social Learning, Discussions, Debates, Co-Creation);

- Open Assessment Methods (e.g., Peer Assessment, Collaborative Assessment, Problem-based Assessment, Project-based Assessment, e-Portfolio);

- Accessibility and Inclusion;

- OERs \& OEPs in specific disciplines (e.g., Languages, STEM, Economics, etc.);

- OERs \& OEPs in specific languages (e.g., English, Chinese, Hindi, Spanish, French, Arabic, etc.);

- OERs \& OEPs in Lifelong Learning;

- OERs \& OEPS Skills' Certification and Accreditation;

Module \#1 includes introductory material (definitions, types, benefits, challenges, and costs) about OERs as well as open licenses, intellectual property rights and copyrights issues. Regarding module $\# 2$, it is not a trivial task to find an OER suitable for a specific course, teacher, and students. Although important efforts have been made and are continuously made, there is not a comprehensive directory, meta-search engine, or repository (e.g., Merlot, 2020; OASIS, 2020; OER Commons, 2020; OpenDOAR, 2020) where a teacher can easily find an appropriate OER for his/her class on any subject at any educational level and language. So, it is important to train the teachers on the high variety of directories and repositories that contain open courses, educational modules, lesson plans, activities, assignments, assessment, textbooks, video lectures, podcasts, games and many other forms of educational material. 
A teacher should know the available OERs repositories, and be able to search them, locate appropriate OERs, explore candidate OERs, and understand their characteristics, properties and functionalities. In addition, the teacher should be able to identify the intellectual property rights of any OER.

It is also very important that the teacher should be able to evaluate the OER according to appropriate criteria (e.g., Economides \& Perifanou, 2018a, b; Perifanou et al., 2020). For example, a teacher should be able to evaluate the openness, authenticity, credibility, clarity, relevance, usefulness, ease-of-use, appearance, safety, and other characteristics of the OERs. Special attention should be given to the validity and reliability of the content since a lot of disinformation is circulated lately.

After selecting an appropriate OER, the teacher should be able to use it (module \#3). This includes downloading, storing, and curating it on various devices (e.g., mobile phone, laptop, desktop computer, LMS, institutional repository). Then the teacher should be able to schedule and use it in teaching and learning. Finally, if the OER becomes obsolete, the teacher should be able to withdraw and replace it with another appropriate OER. The teachers should not be locked in an inappropriate OER.

Regarding module \#4, the teacher should be able to openly interact, communicate, collaborate with students and peers using OERs. Also, the teacher should be able to share OERs with students and peers, as well as teach, support, and assess students using OERs.

Then, in module $\# 5$, the teacher should be able to modify, combine, and correct existing OERs. In addition, the teacher should be able to design, develop, and create new OERs. Finally, the teacher should be able to apply open licenses (e.g., Creative Commons) and copyrights to OERs as well as protect students and peers using OERs and from inappropriate OERs.

Finally, module \#6 contains material related to Open Educational Practices (OEPs). The teacher should be able to apply Open Pedagogies, Open Teaching and Assessment methods that are inclusive. Since different teachers teach different subjects (e.g., humanities, social sciences, natural sciences, law, medicine) in various languages, specific guidelines should be given to teachers according to the specific needs of the specific subject and language (as well socio-economic context).

Concluding, let define OERs \& OEPs competence to be the person's knowledge, skills and attitudes to 'efficiently' find, evaluate, use, create, and share OERs \& OEPs, as well as communicate and collaborate with others using open digital technologies, OERs \& OEPs in order to achieve specific goals. In other words, an OERs \& OEPs competent teacher should be able to find, evaluate, use, create, and share OERs \& OEPs, communicate and collaborate with students and peers using open digital technologies, OERs \& OEPs as well as utilize open pedagogies, teaching, and assessment methods.

\section{Conclusions and future research}

In order to not discriminate students regarding their access to educational resources that may cost a lot, educational authorities should develop educational policies and strategies of adopting Open Educational Resources (OERs) at all disciplines and levels of education. In order to efficiently integrate OERs \& OEPs in the teaching practice, pre-service and in-service teachers should be trained in utilizing OERs \& OEPs. This paper proposes a framework for teachers' training syllabus on OERs \& OEPs. Educational policy officials and training authorities may use this framework to design training programmes for teachers on how to integrate OERs in their teaching.

Features studies may investigate the impact of teachers' training programmes on teachers' competence to integrate OERs \& OEPs in their teaching practice. Also, investigation among different disciplines would shed light on the difficulties and obstacles that teachers of different disciplines face. For example, what is the level of difficulty in finding OERs for teaching economics, law, biology, Italian language, or philosophy?

\section{References}

Blomgren, C. (2018). OER awareness and use: The affinity between higher education and K-12, The International Review of Research in Open and Distributed Learning, Vol. 19 No. 2, doi: 10.19173/ irrodl.v19i2.3431.

Economides, A. A. \& Perifanou, M. (2018a). Dimensions of openness in MOOCs \& OERs. In: EDULEARN2018 Proceedings, 10th International Conference on Education and New Learning Technologies, pp. 3684-3693. 2-4 July, Palma Spain, IATED Digital library. DOI: $10.21125 /$ edulearn.2018.0942

Economides, A. A., \& Perifanou, M. A. (2018b). MOOC affordances model. In: 2018 IEEE Global Engineering Education Conference (EDUCON) (pp. 599-607). DOI: 10.1109/EDUCON.2018.8363285 
Kimmons, R. (2015). OER Quality and adaptation in K-12: Comparing teacher evaluations of copyright-restricted, open, and open/adapted textbooks. The International Review of Research in Open and Distributed Learning, 16(5). DOI: 10.19173/irrodl.v16i5.2341

Merlot (2020). Retrieved October 10, 2020 from: https://www.merlot.org/merlot/

OASIS (2020). Retrieved October 10, 2020 from: https://oasis.geneseo.edu/

OECD (2017). Giving knowledge for free: The emergence of Open Educational Resources. ISBN: $\quad 9789264032125 . \quad$ Retrieved June 10, 2019 from: http://www.oecd.org/education/ceri/38654317.pdf

OECD (2020). Lessons for education from COVID-19. A policy maker's handbook for more resilient systems. Retrieved June 10, 2019 from: http://www.oecd.org/education/lessons-for-educationfrom-covid-19-0a530888-en.htm

OER Commons (2020). Retrieved October 10, 2020 from: https://www.oercommons.org/

OpenDOAR (2020). Retrieved October 10, 2020 from: https://v2.sherpa.ac.uk/opendoar/

OpenLang Network Platform (2020). Retrieved October 10, 2020 from: https://openlangnetwork.kmi.open.ac.uk/

OpenLang Network Project (2020). Retrieved October 10, 2020 from: https:/www.openlangnet.eu/

Perifanou, M., Kosmas, P., Parmaxi, A. \& Economides, A.A. (2021). The challenge of creating the Openlang Network's online open database of 24 European language placements tests. In: 15th annual International Technology, Education and Development Conference (INTED) 2021, 8-9 March, IATED Publ.

TALIS (2018). The OECD Teaching and Learning International Survey. Retrieved October 10, 2020 from: https://www.oecd.org/education/talis/

UNESCO (2019). Recommendation on Open Educational Resources (OER). Retrieved October $\quad 10, \quad 2020 \quad$ from: $\quad$ http://portal.unesco.org/en/ev.php-

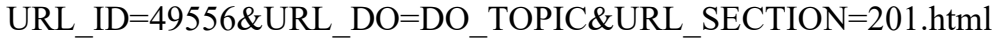

UNESCO (2020). COVID-19 Impact on Education. Retrieved October 10, 2020 from: https://en.unesco.org/covid19/educationresponse 